\title{
Predictive Vector Selector for Direct Torque Control of Matrix Converter fed Induction Motors
}

\author{
Carlos Ortega \\ Electronic Department \\ Escola Universitària Salessiana de Sarrià \\ Email: cortega@euss.es
}

\author{
Antoni Arias \\ and Jordi Espina \\ Electronic Department \\ Universitat Politècnica de Catalunya \\ Email: arias@eel.upc.edu
}

\begin{abstract}
In this paper, a Direct Torque Control method for Matrix Converters fed Induction Motors is proposed. A predictive algorithm which ensures minimum torque ripple is employed for the selection of the appropriate voltage vector from the Matrix Converter. A new look-up table for Direct Torque Control using Matrix Converters has been developed which delivers a set of three vectors, at every sample period, that fulfil the torque and flux demands. The predictive algorithm computes the torque error that would be present applying each vector and selects the one that contributes with the minimum error. Simulation results, which confirm the good performance of the novel predictive Direct Torque Control using Matrix Converters are shown.
\end{abstract}

\section{INTRODUCTION}

Direct Torque Control (DTC) [1] and Direct Self Control [1] were introduced for Voltage Source Inverters (VSI) drives in 1986 and 1988 respectively. Since then, DTC has gained popularity and nowadays is widely recognized as a high performance technique to control Induction Motors (IM) [2]. However, some research is still being done to adapt DTC to new electrical motors and power converters and also to reduce the electromagnetic torque ripple, which is one of its main drawbacks [3]. The limited number of voltage vectors available from traditional drive power converters makes the torque ripple more challenging. This has prompted a number of researchers to utilize improved multilevel converters that allow a higher number of voltage vectors [4], [5], [6].

Recently, MCs have emerged to become an attractive alternative to the conventional VSI [7], [8], specially in applications where size and weight are relevant issues [9], [10]. The use of MCs in DTC of IM was proposed in [11]. A new look-up table exploiting the higher number of voltage vectors of MCs was proposed in [12] in order to reduce the torque ripple of an IM DTC drive without the introduction of space vector modulation techniques.

Lately, predictive control methods [13], [14], [15] have been investigated to face the challenge of controlling several variables of VSI fed electrical drives. In [16], a Model Based Predictive Control (MPC) directly controls the flux and torque of an IM fed by a MC. The selection of the switching state of the MC is performed by means of a quality function that considers 27 set of predictions; One for each of the 27 permitted states of the MC.

This paper proposes a new look-up table for DTC using MCs which delivers a set of three switching states every sampling interval. Based on the torque prediction for each of the delivered states, the system selects the one that introduces less error in the next sampling interval allowing a significant torque ripple reduction.

\section{MATrix CONVERTER}

A MC is an AC-AC converter, with $m \times n$ bidirectional switches, which connects an m-phase voltage source to an nphase load. The most widely used configuration is the threephase, $3 \times 3$ switches, MC shown in Fig. 1. It connects a three-phase voltage source to a three-phase load. In the MC shown in Fig. $1, v_{S i}$, where $i=A, B, C$, are the phase source voltages, $i_{S i}$ are the phase source currents, $v_{j N}$, where $j=a, b, c$ are the load voltages, $i_{j}$ are the load currents, $v_{i}$ are the MC input voltages and $i_{i}$ are the input currents. A switch, $S_{i j}$ can connect input phase $i$ to the output phase $j$ of the load. With a suitable switching strategy, arbitrary voltages $v_{j N}$ at an arbitrary frequency can be synthesized. Switches are characterized by the following equation:

$$
S_{i j}= \begin{cases}0 & \text { if switch } S_{i j} \text { is open } \\ 1 & \text { if switch } S_{i j} \text { is closed }\end{cases}
$$

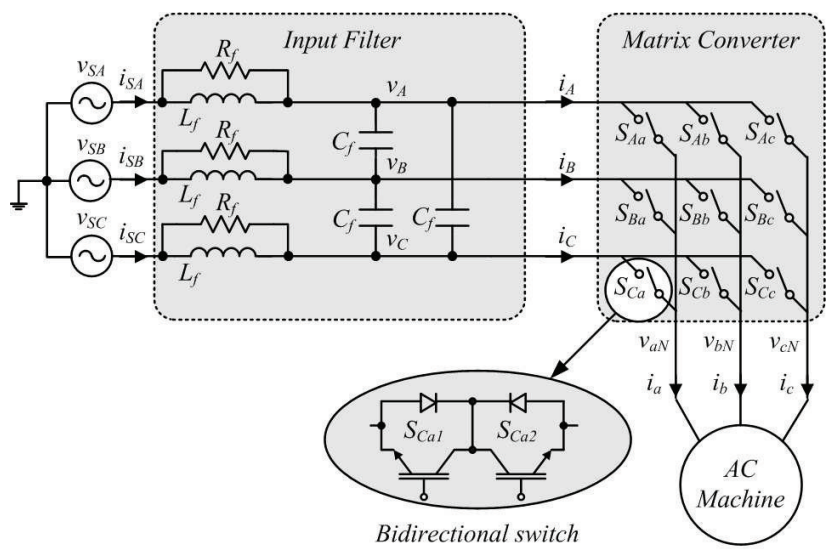

Fig. 1. $3 \times 3$ Matrix Converter.

The permitted switching states of a $3 \times 3 \mathrm{MC}$ are shown in table I, and have been classified in groups. The first three groups containing the states $( \pm 1, \pm 2, \pm 3),( \pm 4, \pm 5$, 
TABLE I

Voltage AND CURRENT Vectors OF A $3 \times 3$ MC

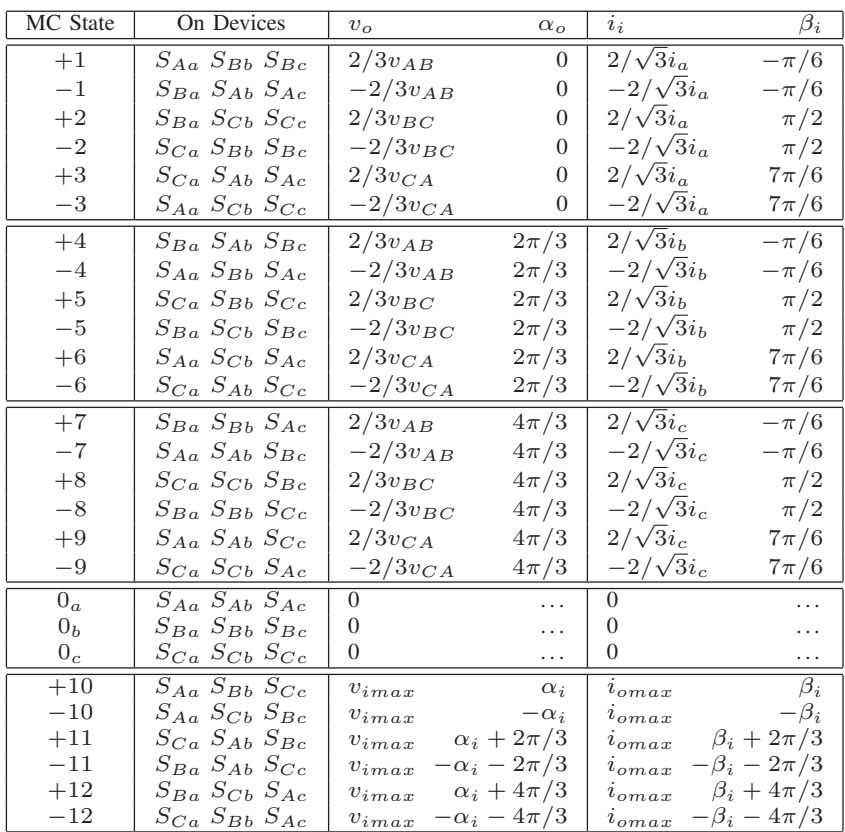

$\pm 6)$, and $( \pm 7, \pm 8, \pm 9)$, produces active vectors of variable amplitude, depending on the line-to-neutral voltage, but at stationary position (pulsating vectors). States $0_{a}, 0_{b}$ and $0_{c}$, corresponding to group 4, connecting all the output lines to the same input line, are the corresponding zero vectors. The last six states (group 5), providing a direct connection of each output line to a different input line, are the rotating vectors.

\section{SySTEM ModeL}

Since the proposed method can be considered a MPC, a mathematical model representing the real system with sufficient accuracy is necessary. Based on the models, the behavior of variables of interest can be predicted actuating in consequence.

\section{A. Matrix Converter Model}

The state of the converter switches can be represented by means of the so-called transfer matrix $T$ which has the following form:

$$
T=\left[\begin{array}{lll}
S_{A a}(t) & S_{B a}(t) & S_{C a}(t) \\
S_{A b}(t) & S_{B b}(t) & S_{C b}(t) \\
S_{A c}(t) & S_{B c}(t) & S_{C c}(t)
\end{array}\right]
$$

Each row shows the state of the switches connected to the same output line while each column shows the state of the switches connected to the same input line. Due to the instantaneous power transfer of MCs, voltages and currents in one side may be reconstructed, at any instant, by means of the corresponding voltages and currents in the other side
[17]. Because the MC is connected to the grid, the input lineto-neutral voltages are known, therefore, applying Kirchhoff's voltage law in Fig. 1, the output line-to-neutral output voltages are found as follows:

$$
\left[\begin{array}{l}
v_{a N}(t) \\
v_{b N}(t) \\
v_{c N}(t)
\end{array}\right]=\left[\begin{array}{lll}
S_{A a}(t) & S_{B a}(t) & S_{C a}(t) \\
S_{A b}(t) & S_{B b}(t) & S_{C b}(t) \\
S_{A c}(t) & S_{B c}(t) & S_{C c}(t)
\end{array}\right]\left[\begin{array}{l}
v_{A}(t) \\
v_{B}(t) \\
v_{C}(t)
\end{array}\right]
$$

The output current results from applying these output voltages to a given load. Measuring the output currents and applying Kirchhoff's current law, the input currents can be easily found:

$$
\left[\begin{array}{l}
i_{A}(t) \\
i_{B}(t) \\
i_{C}(t)
\end{array}\right]=\left[\begin{array}{lll}
S_{A a}(t) & S_{A b}(t) & S_{A c}(t) \\
S_{B a}(t) & S_{B b}(t) & S_{B c}(t) \\
S_{C a}(t) & S_{C b}(t) & S_{C c}(t)
\end{array}\right]\left[\begin{array}{c}
i_{a}(t) \\
i_{b}(t) \\
i_{c}(t)
\end{array}\right]
$$

As it can be seen in (4), in order to find the input currents the transpose transfer matrix $T^{T}$ is applied.

$$
T^{T}=\left[\begin{array}{lll}
S_{A a}(t) & S_{A b}(t) & S_{A c}(t) \\
S_{B a}(t) & S_{B b}(t) & S_{B c}(t) \\
S_{C a}(t) & S_{C b}(t) & S_{C c}(t)
\end{array}\right]
$$

\section{B. Induction Motor Model}

The dynamic model of the IM referred to the stator has been widely studied [2]. The space vector representation of the stator and rotor equations can be written in the stator reference frame as:

$$
\begin{gathered}
\overrightarrow{v_{s}}=R_{s} \overrightarrow{i_{s}}+\frac{d}{d t} \overrightarrow{\psi_{s}} \\
\overrightarrow{v_{r}}=0=R_{r} \overrightarrow{i_{r}}+\frac{d}{d t} \overrightarrow{\psi_{r}}-j \omega \overrightarrow{\psi_{r}}
\end{gathered}
$$

where $R_{s}$ and $R_{r}$ are the stator and rotor resistances, $\overrightarrow{\psi_{s}}$ and $\overrightarrow{\psi_{r}}$ are the stator and rotor fluxes and $\omega$ is the rotor angular frequency.

The stator and rotor fluxes are related with the stator and rotor currents by means of the following equations:

$$
\begin{aligned}
& \overrightarrow{\psi_{s}}=L_{s} \overrightarrow{i_{s}}+L_{m} \overrightarrow{i_{r}} \\
& \overrightarrow{\psi_{r}}=L_{m} \overrightarrow{i_{s}}+L_{r} \overrightarrow{i_{r}}
\end{aligned}
$$

where $L_{s}$ and $L_{r}$ are the stator and rotor self inductances, and $L_{m}$ is the mutual inductance.

The electromagnetic torque developed by the motor can be expressed as follows:

$$
T_{e}=\frac{3}{2} p \frac{L_{m}}{\sigma L_{s} L_{r}}\left[\overrightarrow{\psi_{s}} \cdot j \overrightarrow{\psi_{r}}\right]
$$

where $p$ is the number of pole pairs of the IM.

Resolving for $\overrightarrow{i_{s}}$ and $\overrightarrow{i_{r}}$ in (8) and (9), and substituting in (6) and (7), the IM can be modeled with stator and rotor fluxes as the state variables by the following equation: 
TABLE II

$$
\left[\begin{array}{l}
\frac{d}{d t} \vec{\psi}_{s} \\
\frac{d}{d t} \vec{\psi}_{r}
\end{array}\right]=\left[\begin{array}{cc}
-\frac{R_{s}}{\sigma L_{s}} & \frac{R_{s} L_{m}}{\sigma L_{s} L_{r}} \\
\frac{R_{r} L_{m}}{\sigma L_{s} L_{r}} & \left(j \omega-\frac{R_{r}}{\sigma L_{r}}\right)
\end{array}\right] \cdot\left[\begin{array}{l}
\overrightarrow{\psi_{s}} \\
\overrightarrow{\psi_{r}}
\end{array}\right]+\left[\begin{array}{l}
1 \\
0
\end{array}\right] \overrightarrow{v_{s}}
$$

In order to predict the the flux and torque values for the next sampling instant $t(k+1)$, a discrete-time set of equations can be derived from the continuous-time model. For small values of the control sampling time $T_{s}$, the stator and rotor fluxes at $t(k+1)$ can be calculated as follows:

$$
\begin{aligned}
& \vec{\psi}_{s}(k+1)=\vec{\psi}_{s}(k)+\frac{d}{d t} \vec{\psi}_{s}(k) T_{s} \\
& \vec{\psi}_{r}(k+1)=\vec{\psi}_{r}(k)+\frac{d}{d t} \vec{\psi}_{r}(k) T_{s}
\end{aligned}
$$

Substituting (12) and (13) in (11) yields:

$$
\begin{gathered}
\overrightarrow{\psi_{s}}(k+1)= \\
\overrightarrow{\psi_{s}}(k)+\left(-\frac{R_{s}}{\sigma L_{s}} \overrightarrow{\psi_{s}}(k)+\frac{R_{r} L_{m}}{\sigma L_{s} L_{r}} \overrightarrow{\psi_{r}}(k)+\overrightarrow{v_{s}}(k)\right) T_{s} \\
\overrightarrow{\psi_{r}}(k+1)= \\
\overrightarrow{\psi_{r}}(k)+\left[\frac{R_{r} L_{m}}{\sigma L_{s} L_{r}} \vec{\psi}_{s}(k)+\left(j \omega(k)-\frac{R_{r}}{\sigma L_{r}}\right) \vec{\psi}_{r}(k)\right] T_{s}
\end{gathered}
$$

Substituting (14) and (15) in (10) the torque slope at instant $t(k+1)$ is obtained:

$$
\begin{gathered}
m_{T e}=\frac{\Delta T e(k+1)}{\Delta t}=-T e\left(\frac{R_{s}}{\sigma L_{s}}+\frac{R_{r}}{\sigma L_{r}}\right)+ \\
\frac{3}{2} p \frac{L_{m}}{\sigma L_{s} L_{r}}\left[-v_{\alpha s} \psi_{\beta r}+v_{\beta s} \psi_{\alpha r}-\omega\left(\psi_{\alpha s} \psi_{\alpha r}+\psi_{\beta s} \psi_{\beta r}\right)\right]
\end{gathered}
$$

where $\Delta t=T s$ is the sampling interval.

Notice that the sampling instant $t(k)$ at which all the variables at the right side of (16) has been removed for simplicity.

\section{CONTROL STRATEGY}

From table I, it can be seen that at every sampling interval there will be three MC states that fulfil the DTC requirements [11].

A new look-up table is developed which delivers these three vectors instead of just the one having the largest amplitude. As in [11], the system implements the conventional DTC imposing the voltage vectors that would have been delivered by a VSI $\left(V_{0}\right.$ to $\left.V_{7}\right)$. Depending on the sector in which the input voltage vector lies, table II delivers a set of three MC

\begin{tabular}{|c|c|c|c|c|c|c|}
\hline$V_{V S I}$ & \multicolumn{6}{|c|}{ Sector of Input Voltage Vector } \\
\hline & 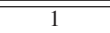 & 2 & 3 & 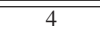 & $\overline{5}$ & 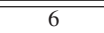 \\
\hline$\overline{V_{1}}$ & -321 & $2-1-3$ & -123 & $3-1-2$ & -231 & $1-2-3$ \\
\hline$V_{2}$ & -987 & $8-7-9$ & -789 & $9-7-8$ & -897 & $7-8-9$ \\
\hline$V_{3}$ & -654 & $5-4-6$ & -456 & $6-4-5$ & -564 & $4-5-6$ \\
\hline$V_{4}$ & $3-2-1$ & -213 & $1-2-3$ & -312 & $2-3-1$ & -123 \\
\hline$V_{5}$ & $9-8-7$ & -879 & $7-8-9$ & -978 & $8-9-7$ & -789 \\
\hline$V_{6}$ & $6-5-4$ & -546 & $4-5-6$ & -645 & $5-6-4$ & -456 \\
\hline
\end{tabular}
states having the same direction of that of the standard VSI vector.

Since the magnitudes of the MC states are different, a set of four torque slopes $\left(m_{T e}\right)$ are calculated using (16); One for a zero vector and three for the vectors delivered by table II. The electromagnetic torque for every vector is predicted at instant $t(k+1)$ as:
NOVEL LOOK-UP TABLE FOR PREDICTIVE DTC USING MCS

TABLE III

INDUCTION MOTOR PARAMETERS.

\begin{tabular}{|c|c|c|c|}
\hline Output power & $1000 \mathrm{~W}$ & Torque & $6.7 \mathrm{Nm}$ \\
\hline Voltage & $380 \mathrm{~V}$ & Pole pairs & 2 \\
\hline Stator resistance & $4.7 \Omega$ & Stator self-inductance & $320 \mathrm{mH}$ \\
\hline Rotor resistance & $5.05 \Omega$ & Rotor self-inductance & $320 \mathrm{mH}$ \\
\hline
\end{tabular}

$$
T_{e}(k+1)=m_{T e} T_{s}
$$

For each torque prediction, the absolute torque error is obtained as:

$$
\left|T_{e}^{e r r o r}\right|=\left|T_{e}^{*}-T_{e}(k+1)\right|
$$

where the superscript "*" denotes the reference value. As shown in Fig. 2, the MC state that generates the minimum absolute torque error is then selected.

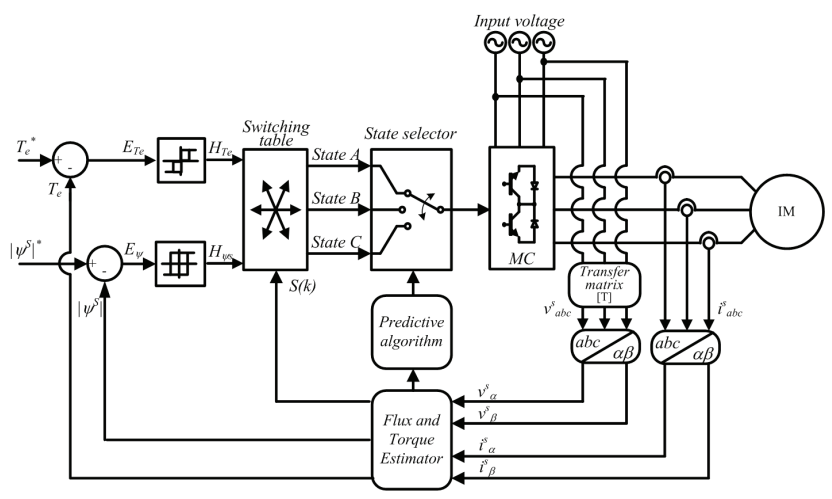

Fig. 2. Block diagram of the proposed predictive DTC.

\section{Simulation Results}

Simulation results for the proposed method has been carried out with the DTC having the following settings:

- Torque reference, $T_{e}^{*}= \pm 6.7 \mathrm{Nm}$ ( \pm rated torque)

- Flux reference, $\left|\psi^{s *}\right|=0.8 W b$ (rated flux)

- Sampling time, $T_{s}=50 \mu \mathrm{s}$

The parameters of the IM employed during the test are shown in table III.

The IM is loaded with a DC machine which controls the rotating speed at $100 \mathrm{rpm}$.

A positive torque reference of $T_{e}^{*}=6.7 \mathrm{Nm}$ is applied to start up. At $t=0.5 \mathrm{~s}$, a torque reversal is applied $\left(T_{e}^{*}=\right.$ $-6.7 \mathrm{Nm})$. 
The performance of the electromagnetic torque and stator flux with the proposed MPC-DTC are shown in Fig. 3. Both the electromagnetic torque and the stator flux follow their respective reference values. It can be seen the fast and decoupled control of both variables achieved with the predictive algorithm. The electromagnetic torque reverses quickly and has a ripple of less than $10 \%$, the standard deviation being $0.1331 \mathrm{Nm}$.
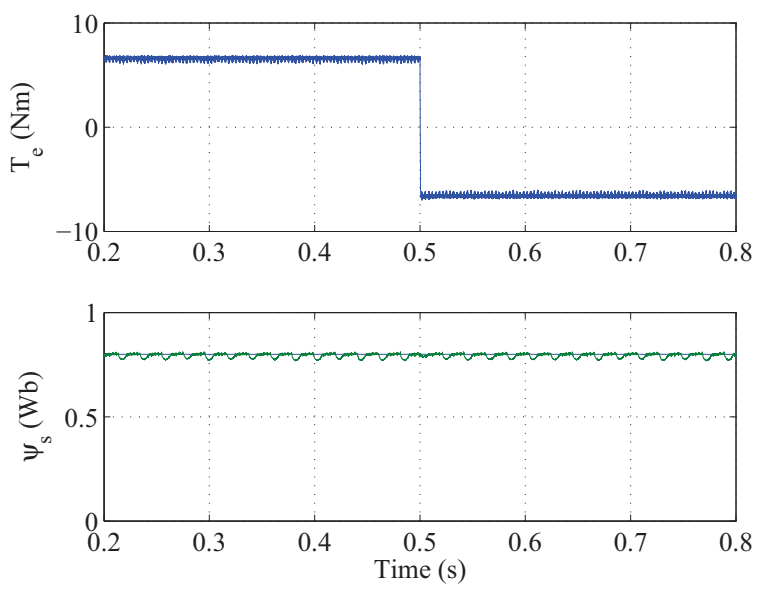

Fig. 3. Step torque response with the proposed MPC-DTC. (a) Electromagnetic torque. (b) Stator flux.

Figure 4 shows the electromagnetic torque and stator flux performance of the standard DTC using MCs without MPC. It can be observed an increase in the electromagnetic torque ripple in comparison to Fig. 3, the standard deviation being $0.2258 \mathrm{Nm}$.
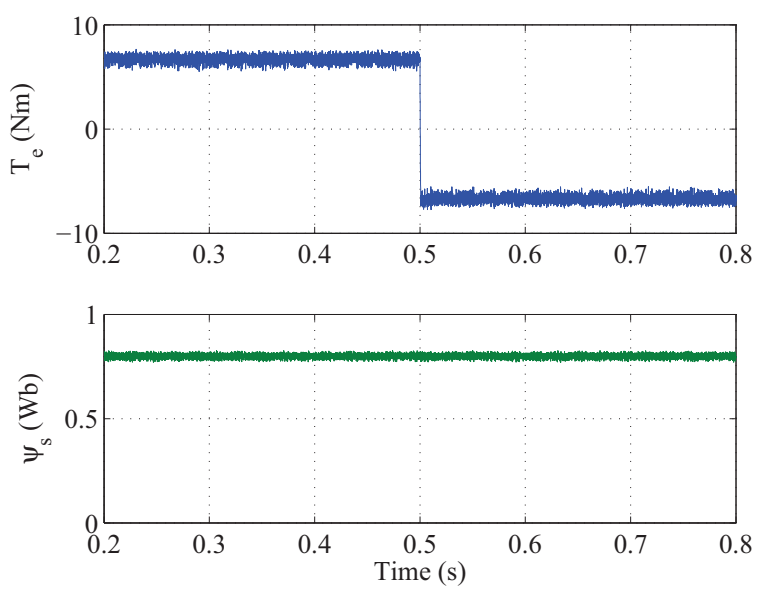

Fig. 4. Step torque response with the standard DTC using MCs. (a) Electromagnetic torque. (b) Stator flux.

The $\alpha-\beta$ components of the stator flux are shown in Fig. 5 and Fig. 6 for the proposed MPC-DTC and the standard
DTC using MCs respectively. The stator flux vector path is also shown, which follows a circular trajectory as in the conventional DTC. Comparing the flux performance of Fig. 5 and Fig. 6, it can be noted that although with less ripple, the proposed MPC-DTC shows a slightly distorted flux trajectory due to the application of voltage vector with lower amplitude.
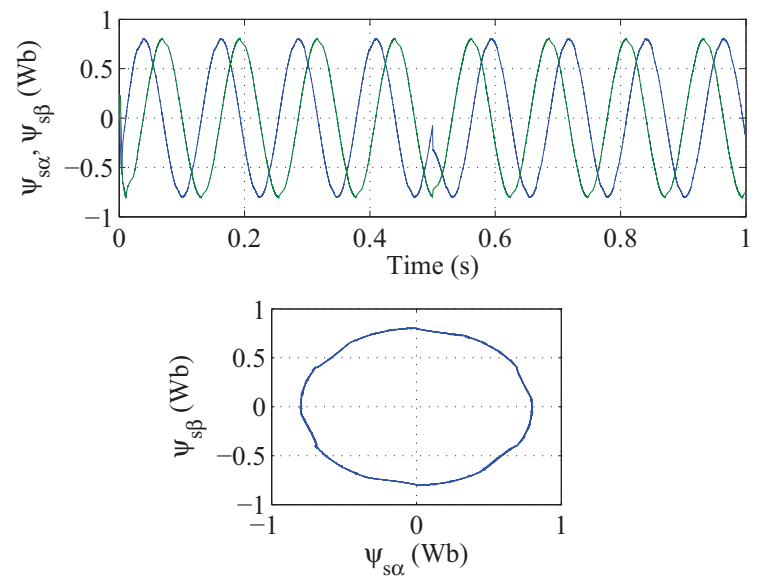

Fig. 5. Stator flux performance with the proposed MPC-DTC. (a) $\alpha-\beta$ components. (b) Stator flux vector path.
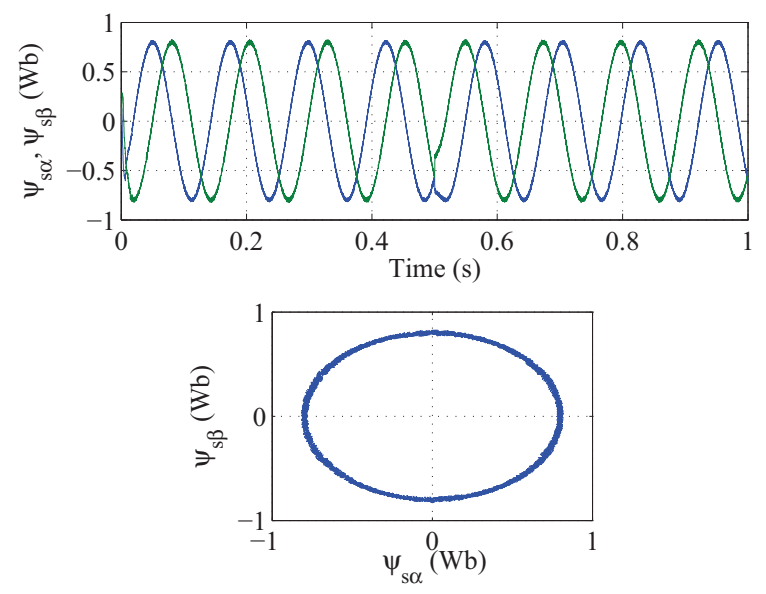

Fig. 6. Stator flux performance with the standard DTC using MCs. (a) $\alpha-\beta$ components. (b) Stator flux vector path.

The stator line-to-neutral voltage and the corresponding phase current of the proposed MPC-DTC are shown in Fig. 7. It is possible to distinguish the high frequency components, due to the MC commutations, from the fundamental frequency of the stator voltage. The sinusoidal behavior of the stator currents proves the indirect control of this variable.

Figure 8 shows the stator line-to-neutral voltage and the corresponding phase current of the standard DTC using MCs. 

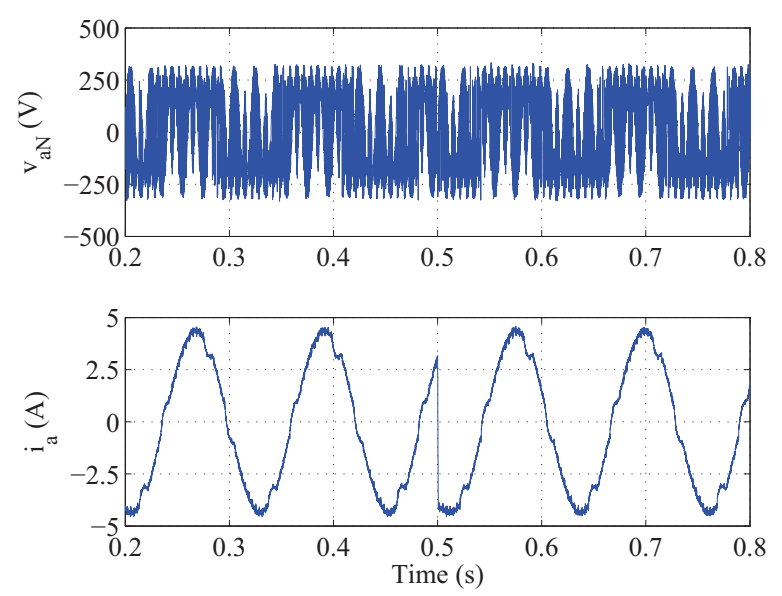

Fig. 7. Stator line-to-neutral voltage and phase current with the proposed MPC-DTC. (a) Phase A stator voltage. (b) Phase A stator current.

The stator current ripple is significantly higher in comparison to the proposed MPC-DTC shown in Fig. 7.
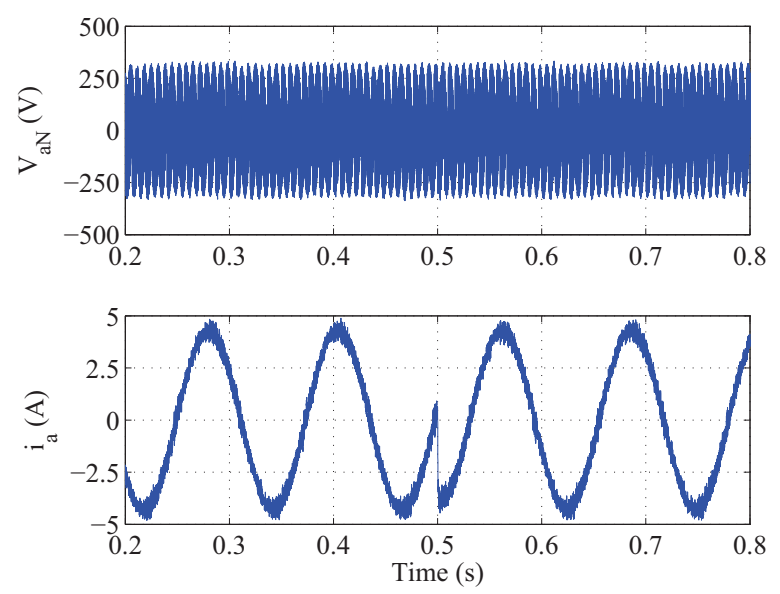

Fig. 8. Stator line-to-neutral voltage and phase current with the standard DTC using MCs. (a) Phase A stator voltage. (b) Phase A stator current.

Finally, the MC states and the corresponding torque slope are presented in Fig. 9 for the proposed MPC-DTC. The electromagnetic torque slope is highly affected by the selected MC state and, as expected, the highest value is found at the instant of the torque step.

\section{CONCLUSION}

A predictive DTC of MC fed IM drives has been presented in this paper. The new look-up table allows the predictive DTC to select, from three different states, the one that ensures the minimum torque error. It has been shown the effectiveness and simplicity of the method achieving fast and decoupled control of torque and flux with considerable low ripple. Comparing
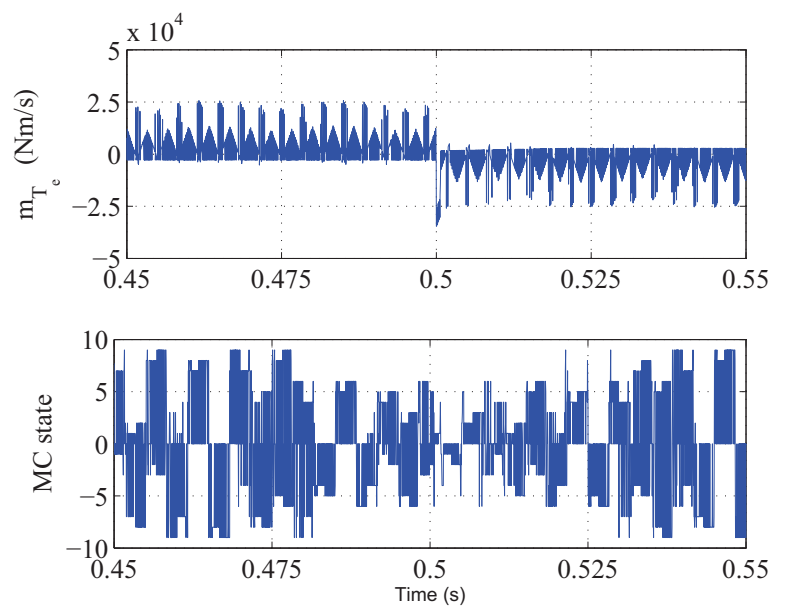

Fig. 9. Selected MC states and torque slope. (a) Torque slope. (b) MC state.

the proposed MPC-DTC with the standard DTC using MCs, an improvement of more than $41 \%$ in the toque ripple has been achieved.

\section{ACKNOWLEDGMENT}

The authors would like to thank the support provided by the "Ministerio de Ciencia y Tecnología de España" under the TEC 2004-00589 Research Project.

\section{REFERENCES}

[1] I. Takahashi and T. Nogushi, "A new quick-response and high-efficiency control strategy of an induction motor," IEEE Transactions on Industry Applications, pp. 820-827, October, 1986.

[2] Z. Sorchini and P. Krein, "Formal Derivation of Direct Torque Control for Induction Machines," IEEE Transactions on Power Electronics, vol. 21, pp. 1428 - 1436, September, 2006.

[3] G. S. Buja and M. P. Kazmierkowski, "Direct Torque Control of PWM Inverter-Fed AC Motors: A Survey," IEEE Transactions on Industrial Electronics, vol. 51, pp. 744-758, August, 2004.

[4] K. B. Lee, J. H. Song, J. H. I. Choy, and J. Y. Yoo, "Torque Ripple Reduction in DTC of Induction Motor Driven by Three-Level Inverter With Low Switching Frequency," IEEE Transactions on Power Electronics, vol. 17, pp. 255-264, March, 2000.

[5] V. Perelmuter, "Three-level inverters with direct torque control," Proceedings of IEEE Industry Apllication Conference 'O0, vol. 3, pp. 13681374, October, 2000.

[6] A. Sapin, P. K. Steimer, and J. J. Simond, "Modeling, Simulation, and Test of a Three-Level Voltage-Source Inverter With Output LC Filter and Direct Torque Control," IEEE Transactions on Industry Applications, vol. 43, pp. 469 - 475, March/April, 2008.

[7] P. Wheeler, J. Rodriguez, J. Clare, L. Empringham, and A. Weinstein, "Matrix converters: a technology review," IEEE Transactions on Industrial Electronics, vol. 49, pp. 276-288, April, 2002.

[8] P. Wheeler, J. Clare, M. Apap, and K. J. Bradley, "Harmonic Loss Due to Operation of Induction Machines From Matrix Converters," IEEE Transactions on Industrial Electronics, vol. 55, pp. 809 - 816, February, 2008.

[9] C. Klumpner, F. Blaabjerg, and P. Nielsen, "Speeding-up the Maturation Process of the Matrix Converter Technology," Proceedings of PESC'01, vol. 2, pp. 1083 - 1088, June, 2001.

[10] P. Zanchetta, P. Wheeler, J. Clare, M. Bland, L. Empringham, and D. Katsis, "Control Design of a Three-Phase Matrix-Converter-Based AC-AC Mobile Utility Power Supply," IEEE Transactions on Industrial Electronics, vol. 55, pp. 209 - 217, January, 2008. 
[11] D. Casadei, G. Serra, and A. Tani, "The Use of Matrix Converters in Direct Torque Control of Induction Machines," IEEE Transactions on Industrial Electronics, vol. 48, pp. 1057-1064, December, 2001.

[12] C. Ortega, A. Arias, X. del Toro, E. Aldabas, and J. Balcells, "Novel direct torque control for induction motors using short voltage vectors of matrix converters," Proceedings of IECON '05, vol. 1, pp. 1353 - 1358, November, 2005.

[13] J. Rodriguez, J. Pontt, C. Silva, P. Correa, P. Lezana, P. Cortes, and U. Ammann, "Predictive Current Control of a Voltage Source Inverter," IEEE Transactions on Industrial Electronics, vol. 54, pp. 495 - 503, February, 2007.

[14] J. Rodriguez, J. Pontt, C. Silva, P. Cortes, and U. Ammann, "Predictive Direct Torque Control of an Induction Machine," Proceedings of EPEPEMC'04, vol. 1, pp. 2 - 4, September, 2004

[15] P. Correa, M. Pacas, and J. Rodriguez, "Predictive Torque Control for Inverter-Fed Induction Machines," IEEE Transactions on Industrial Electronics, vol. 54, pp. 1073 - 1079, April, 2007.

[16] J. Rodriguez, J. Pontt, R. Vargas, P. Lezana, U. Ammann, P. Wheeler, and F. Garcia, "Predictive Direct Torque Control of an Induction Motor fed by a Matrix Converter," Proceedings of ISIE '07, vol. 1, pp. $1-10$, Sptember, 2007.

[17] L. Empringham, P. Wheeler, and J. L. Clare, "Intelligent Commutation of Matrix Converter Bi-directional Switch Cells using Novel Gate Drive Techniques," Proceedings of PESC '98, vol. 1, pp. 707-713, June/July, 1998. 